\title{
Two sibs with cleft palate, ankyloblepharon, alveolar synechiae, and ectodermal defects: a new recessive syndrome?
}

\author{
A Seres-Santamaria, J L Arimany, F Muñiz
}

\begin{abstract}
Hay and Wells in 1976 reported seven patients from four families who had an inherited condition of which the main features were ankyloblepharon, ectodermal defects, and cleft lip and palate. The inheritance pattern was determined to be autosomal dominant. This condition is known as AEC syndrome or Hay-Wells syndrome.

We report a family with two sibs showing some of these features and congenital adhesions between the upper and lower jaws (alveolar synechiae). There seems to be a recessive pattern of inheritance as neither of the parents has any features of the syndrome. This could be described as a recessive form of Hay-Wells syndrome with additional features or be named as a new syndrome.

( $\mathcal{F}$ Med Genet 1993;30:793-5)
\end{abstract}

Hay and Wells ${ }^{1}$ in 1976 reported seven patients from four families with an inherited condition of which the main features were ankyloblepharon, ectodermal defects, and cleft lip and palate. Ankyloblepharon is a congenital fusion of the eyelids by solid bands. The fusion may be limited to numerous connective tissue strands and is then called ankyloblepharon filiforme adnatum or AFA. ${ }^{2}$ The inheritance pattern appeared to be autosomal dominant. This condition is now known as AEC syndrome or Hay-Wells syndrome. ${ }^{3}$ The HayWells syndrome is an uncommon form of congenital ectodermal dysplasia, and is characterised by coarse, wiry, sparse hair, dystrophic nails, slight hypohidrosis, scalp infections, ankyloblepharon filiforme adnatum, hypodontia, maxillary hypoplasia, and cleft lip and palate.

Department of
Genetics, Clínica
Teknon, Barcelona,
Spain.
A Seres-Santamaria
Department of
Paediatrics, Hospital
General de Catalunya,
Barcelona, Spain.
J L Arimany
F Muñiz
Correspondence to
Dr Seres-Santamaria,
Diagonal 614 $6^{\circ}, 08021$
Barcelona, Spain.
Received 7 December 1993.
Revised version accepted
30 March 1993.

\section{Case report}

A family with two affected sibs is reported. The parents are unrelated; neither parent nor any other member of the family has any ectodermal defect or other trait suggesting one of these syndromes. The parents are healthy and non-consanguineous. The mother is slightly short. There were no previous pregnancies.

\section{CASE 1}

Case 1, an 11 year 7 month old girl, was the product of a term pregnancy with a normal labour and spontaneous vaginal delivery; her birth weight was $2700 \mathrm{~g}$ (between the $3 \mathrm{rd}$ and
10 th centiles). Soon after birth it was observed that her eyelids were fused. She also had synechiae of the upper and lower gums and from these to the inner side of the cheeks, she had a cleft uvula, and her nails were dystrophic.

The eye bands were released surgically and the oral synechiae were removed to allow normal feeding.

She has shown normal physical and mental development; her weight is above the 97th centile and her height on the 90th. She has had no major problems and her intelligence is normal.

Physical examination at 11 years 1 month showed a well developed, prepubertal girl with mild obesity, cleft uvula, some small synechiae involving the gums and the buccal epithelium, pits in the lower lips, onychodystrophy (fingernails and toenails), and coarse hair. The skin was normal, there were no sweating problems, and the teeth were normal.

\section{CASE 2}

Case 2, a 1 year 9 month old boy, was the second child of the family. He was born after a term pregnancy and uneventful delivery. The mother had some spotting during the first trimester. Amniocentesis was carried out at 16 weeks and showed a normal 46,XY male complement. Birth weight was $2860 \mathrm{~g}$ (10th centile), length was $49 \mathrm{~cm}$ (25th to 50th centiles), and head circumference was $34 \mathrm{~cm}$ (50th centile).

Like his sister he was noted to have ankyloblepharon (fig 1), gingival fusion, cleft palate (fig 2), and onychodystrophy. Soon after birth an erythematous macular rash appeared on both hands (fig 3) and on the dorsum of the feet, especially over the first and second toes; this disappeared spontaneously in three days. No other physical defects were noted. He had surgery on his eyes and mouth on the first day of life. The cleft palate was repaired at 18 months.

On physical examination he was a very active child with a normal face apart from a small chin. He also had pits in the lower lip and some synechiae between the gums and the inner part of the buccal mucosa. He has blond, wiry, sparse hair. His fingernails and toenails are dystrophic. He has always been on the 3rd centile for weight and on the 10th for height. Genitalia are normal, he has normal physical and mental development, and no serious health problems. 


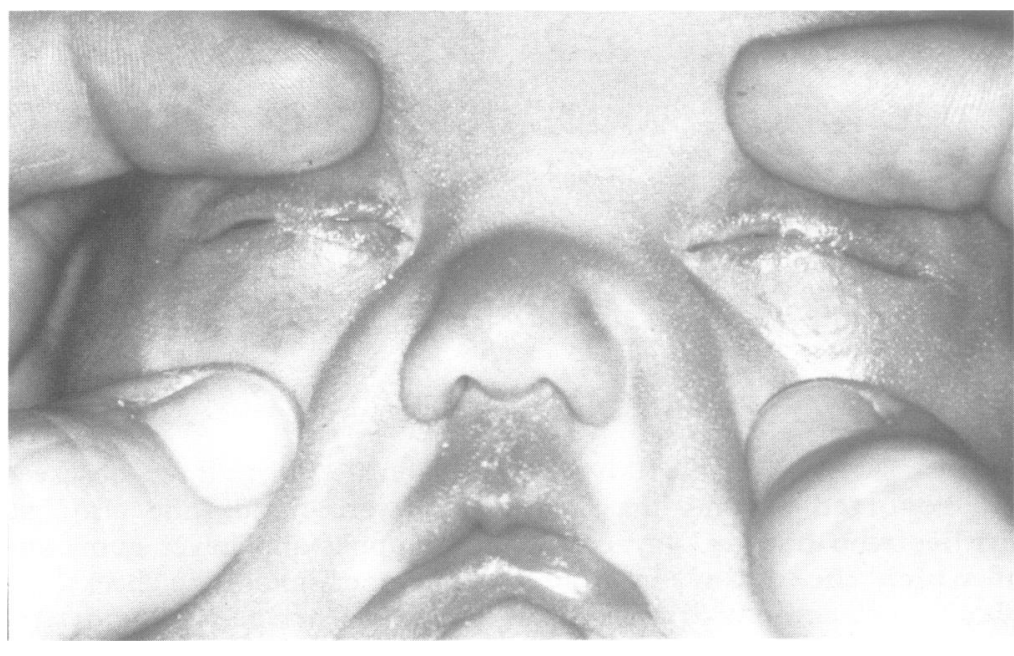

Figure 1 Ankyloblepharon filiforme adnatum in both eyes.

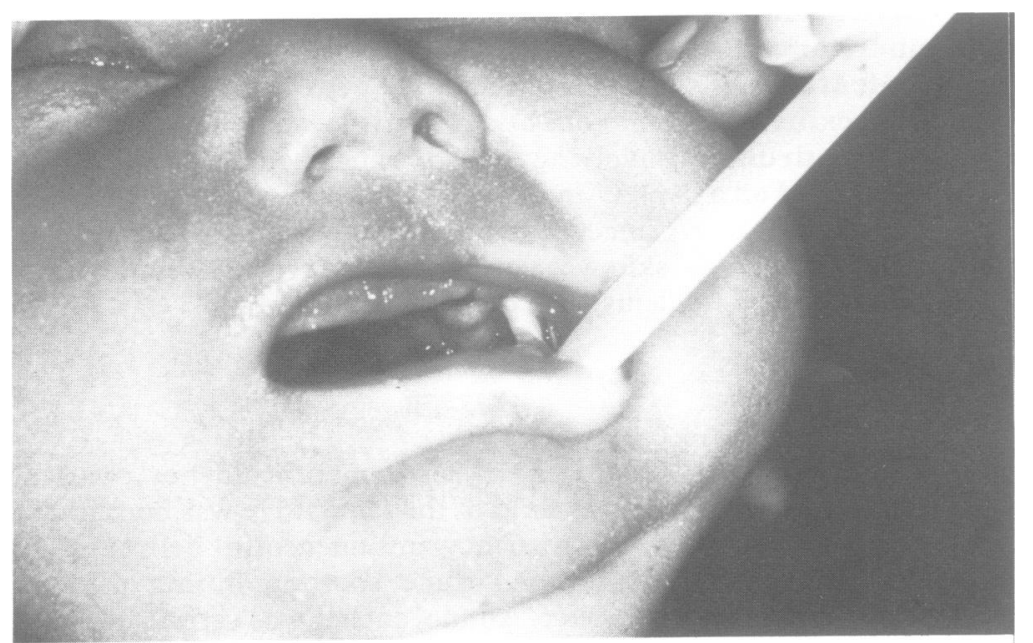

Figure 2 Gingival fusion and cleft palate.

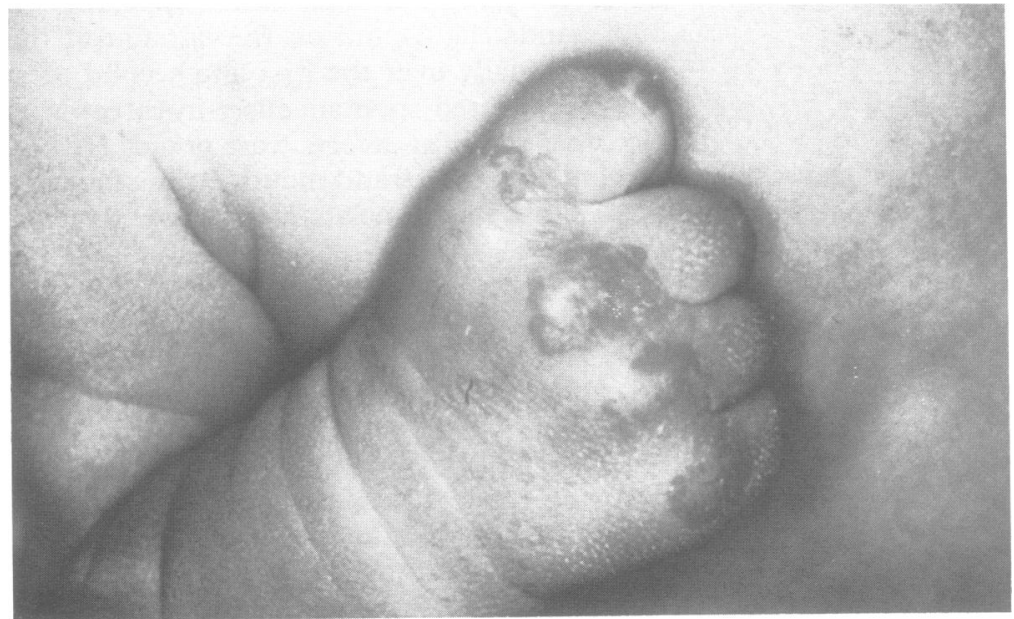

Figure 3 Erythematous macular rash on the right hand.

\section{Discussion}

The Hay-Wells syndrome is characterised by congenital filiform fusion of the eyelids, ectodermal defects, cleft lip/palate, and an autosomal dominant inheritance pattern. Two of the most distinctive, although not unique, findings in Hay-Wells syndrome are the tendency to scalp folliculitis and the ankyloblepharon filiform adnatum. Some features seen occasionally in patients with Hay-Wells syndrome include deafness, lacrimal duct atresia or obstruction, supernumerary nipples, and syndactyly. ${ }^{4}$

Ankyloblepharon has also been seen in other forms of ectodermal dysplasia, such as in curly hair-ankyloblepharon-nail dysplasia (CHANDS) $^{5}$ and Rosselli-Gulienetti syndrome, ${ }^{6}$ but in the first there is no oral cleft, and the second has as the most distinctive features popliteal and perineal pterygia and genital anomalies. ${ }^{4}$

The ectodermal defects in Hay-Wells syndrome can be partial or complete hair loss, coarse, wiry hair, absent or dystrophic nails, pointed, widely spaced teeth, and partial anhidrosis.

Clefting of the palate has been present in nearly all reported patients, but cleft lip is a variable feature. ${ }^{47}$ In some cases there is mental retardation. ${ }^{8}$

The family we report has two affected sibs, a boy and a girl, who have some of the features of Hay-Wells syndrome (table), but they have alveolar synechiae and the inheritance pattern seems to be autosomal recessive as neither of the parents has any ectodermal defect or other trait suggesting one of these syndromes.

Our patients show some similarities to the child reported by Obishi et al, ${ }^{9}$ born to consanguineous parents, with ankyloblepharon, alveolar synechiae, commissural lip pits, hypoplastic nails, and woolly scalp hair, but the child had no cleft uvula/palate as in our patients.

The family we document could be described as having an autosomal recessive variant of Hay-Wells syndrome or, perhaps more likely, having a new syndrome of oral clefting with alveolar synechiae, ankyloblepharon, and ectodermal defects as the main features.

Differences between our patients and AEC syndrome.

\begin{tabular}{lccc}
\hline & Patient & Patient & AEC \\
& 1 & 2 & syndrome \\
\hline Ankyloblepharon & + & + & + \\
Cleft uvula/palate & + & + & + \\
Dystrophic nails & + & + & + \\
Dystrophic hair & + & + & + \\
Alveolar synechiae & + & + & - \\
Lower lip pits & + & + & - \\
Hypodontia/anodontia & - & - & + \\
Partial anhidrosis & - & - & + \\
Aetiology & AR ? & AR ? & AD \\
\hline
\end{tabular}

1 Hay RJ, Wells RS. The syndrome of ankyloblepharon, ectodermal defects and cleft lip and palate: an autosomal dominant condition. Br $\mathcal{\text { J Dermatol 1976;94:277-89. }}$

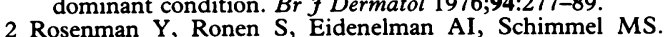
Ankyloblepharon filiforme adnatum: congenital eyelidAnkyloblepharon filiforme adnatum: congenital

3 Spiegel J, Colton A. AEC syndrome: ankyloblepharon, ecto- 
dermal defects and cleft lip and palate. 7 Am Acad Dermatol 1985;12:810-15.

4 Greene SL, Michels VV, Doyle JA. Variable expression in ankyloblepharon-ectodermal defects-cleft lip and palate syndrome. Am f Med Genet 1987;27:207-12.

5 McKusick VA. CHANDS (curly hair-ankyloblepharonectodermal defects-nail dysplasia syndrome *21535). In: Mendelian inheritance in man: catalogs of autosomal dominant, autosomal recessive, and $X$-linked phenotypes. 8th ed. Baltimore: Johns Hopkins University Press, 1988:860.
6 Rosselli D, Gulienetti R. Ectodermal dysplasia. Br 7 Plast Surg 1961;14:190-204.

7 Shwayder TA, Lane AT, Miller ME. Hay-Wells syndrome. Pediatr Dermatol 1986;3:399-504.

8 Bowen P, Armstrong HB. Ectodermal dysplasia, mental retardation, cleft lip/palate and other anomalies in three sibs. Clin Genet 1976;9:35-42.

9 Obishi M, Kai S, Ozeki S, Tashiro H. Alveolar synechia, ankyloblepharon, and ectodermal disorders: an autosomal recessive disorder? Am f Med Genet 1991;38:13-15. 